\title{
SVD Applied to Voltage Sag State Estimation
}

\author{
Araceli Hernández, Member, IEEE, Elisa Espinosa-Juárez, Member, IEEE, Rosa María de Castro, \\ Mohamed Izzeddine
}

\begin{abstract}
The method presented in this paper addresses the problem of voltage sag state estimation (VSSE). The problem consists in estimating the voltage sags frequency at non-monitored buses from the number of sags measured at monitored sites. Usually, due to limitations on the number of available voltage sag monitors, this is an underdetermined problem. In this approach, the mathematical formulation presented is based on the fault positions concept and is solved by means of the Singular Value Decomposition (SVD) technique. The proposed estimation method has been validated by using the IEEE 118 test system and the results obtained have been very satisfactory.
\end{abstract}

Index Terms - voltage sags (dips), power quality monitoring, power system, Power Quality.

\section{INTRODUCTION}

$\mathrm{V}$ OLTAGE sags (also known as voltage dips) are a frequent power quality disturbance that can cause failure or malfunctioning to very common devices used in industrial and tertiary sectors.

This disturbance, as with other power quality problems, must be approached from a compatibility point of view that requires characterizing the equipment sensitivity as well as the power system behavior. This paper relies on this second aspect.

In order to describe the voltage sags performance in the power system, a method must be established that can provide representative values of the expected number and characteristics of voltage sags at system buses. To quantify the system behavior, a great emphasis has been placed recently on the use of different quality indices. Some of these indices are defined at a site level (for a specific point of the supply system), but there are others defined at a system level (for the whole system) [1]-[4]. For assessing site indices, monitoring the power supply at the site of interest can directly provide the information to evaluate the index. However, in order to calculate voltage sag indices of the whole system, ideally the monitoring of all sites should be required. Clearly, such a monitoring program is not economically justifiable.

This work has been financed by the Ministerio de Ciencia e Innovación (MICINN), Spain, under project ENE2010-17459 (CON)

A. Hernández, R. M. de Castro and M. Izzeddine are with the Department of Electrical Engineering, Escuela Técnica Superior de Ingenieros Industriales, Universidad Politécnica de Madrid, Madrid 28006, Spain (e-mail: araceli.hernandez@upm.es, rosamaria.decastro@upm.es mohamed.izzeddine@upm.es).

E. Espinosa-Juárez is with the Electrical Engineering Faculty, Universidad Michoacana de San Nicolás de Hidalgo, Morelia 58060, México (e-mail: eejuarez@umich.mx).
An alternative approach to characterize the system performance is by using stochastic prediction methods. These methods have been widely discussed over the last decade. They are usually based on estimating the expected frequency of occurrence of voltage sags for each site by using the fault statistic rates recorded over a long period [1],[5]-[7]. The probabilistic nature of these stochastic methods makes them mainly suitable for long-term estimations. However, in a specific year, the predicted number of voltage sags, because of the high variability of annual fault rates, can differ substantially from the experienced number.

Recently, some studies have been presented using a "hybrid" approach between monitoring and simulation. These methods are based on estimating the voltage sag performance at non-monitored buses by using the monitoring data collected at a limited number of metering points [8]-[10]. Some authors designate these methods as "state estimation methods," for similarity with the conventional state estimation where the system state is obtained from the available measurements. However, conversely to conventional state estimation methods which are usually overdetermined (the number of measurements is greater than the number of state variables), in this approach an underdetermined problem must be solved. To solve this problem, in [8] a VSSE method is proposed that estimates the voltage profile of a feeder by using the data of a limited number of metering points. This is achieved by making use of the radial connection characteristic of a distribution feeder. However, this approach is not extended for meshed systems. In [9], VSSE is solved by means of Integer Linear Programming (ILP), whereas in [11] Genetic Algorithms (GA) are used to find the solution of the estimation problem. In both of these works, the formulated equations system is obtained by applying an analytical method [7] that determines the limits of some portions of the network to which the state variables are allocated.

The method proposed here presents a much simpler mathematical approach based in the concept of "fault positions" usually applied in stochastic methods. In comparison to [9] and [11], in this approach the equations are straightly determined according to the number of fault positions selected. In addition, the method proposed here to find the solution is Singular Value Decomposition, a technique that has already been used for similar problems regarding other power quality disturbances [13]-[16] and that presents advantageous characteristics with respect to IPL and GA. One of these advantages is that, contrary to ILP and GA, SVD is not an iterative method and, thus, it is not exposed to convergence problems and it always provides a solution, whatever the size and type of the network. In terms of computing time consumption, the solution by means of SVD is also very beneficial with 
almost negligible computation time compared to GA and, specially, to ILP.

This paper is organized as follows. In Section II, the overall mathematical approach used is briefly described to provide a general overview. The proposed formulation based on the fault positions concept is described in detail in Section III. The resolution of equations by means of SVD is presented in Section IV. Section V describes some additional considerations about the presented work, including aspects to be considered in further developments. Finally, in Section VI, several case studies are presented for the IEEE 118 bus test system. In these cases, a random distribution of faults spread through the system has been assumed. Some buses have been selected as monitored buses, and the number of sags has been estimated for the rest of the buses, obtaining very satisfactory results.

\section{FUNDAMENTALS OF THE VSSE MATHEMATICAL FORMULATION}

In conventional state estimation, the following general mathematical formulation is used [17]:

$$
\mathbf{H}=\mathbf{M X}+\mathbf{E}
$$

Here, this expression is used to deal with a different problem, which is the estimation of voltage sags. This mathematical approach has already been used for the state estimation of other power quality disturbances [13]-[16]. In particular, the expression (1) is used for the estimation of voltage sags in [9] where the system equations are obtained by means of an analytical method. Here, similarly to [9], the expression (1) will be used to approach the VSSE problem but, in this case, the system equations will be obtained in a much simpler way by applying the concept of fault positions. Next, the meaning of the terms of (1) is explained for this application:

- $\quad \mathbf{H}$ is a vector formed by measurements.

In this application, analogously to [9], the elements of $\mathbf{H}$ indicate the number of voltage sags recorded at monitored sites. In general, voltage sags with residual voltage below a threshold will be considered.

- $\quad \mathbf{X}$ is the state vector to be estimated.

In this approach, the definition of $\mathbf{X}$ is based on the fault positions concept. The elements of $\mathbf{X}$ are state variables that indicate the number of faults occurred at a line segment associated with a fault position [12].

- $\quad \mathbf{M}$ is a binary matrix that relates the state variables to the measurements.

- $\quad \mathbf{E}$ is the vector of measurement noise.

In this approach, the measurement noise $\mathbf{E}$ in (1) will be initially neglected [13]. The rest of the aforementioned terms of (1) will be explained with more detail in the following section.

\section{FORMULATION BASED ON THE FAULT POSITION CONCEPT}

Following sections describe the construction of the terms of (1) according to the proposed approach.

From here on, a generic electrical system with $N$ buses and $L$ lines will be assumed. The number of monitored sites is denoted by $M$, and in our problem, we will consider that $M<N$.

\section{A. Construction of Vector $\mathbf{H}$}

Measurements vector of (1) is formed by using the data collected at the $\mathrm{M}$ monitored buses by the voltage sags monitors and, in particular, by using the residual voltage recorded during the sag. In the case of unbalanced faults, the considered voltage sag residual magnitude is the lowest value of all phases of the sag, as frequently assumed.

For a given voltage threshold $t$, a vector $\mathbf{H}^{\mathrm{t}}$ will be formed. Each element of this vector is obtained by counting the number of recorded events whose remaining voltage is below the threshold $t$. Therefore, each element of $\mathbf{H}^{\mathrm{t}}$ is an integer number that indicates the number of voltage sags with residual voltage below $t$. Vector $\mathbf{H}^{\mathrm{t}}$ has $M$ elements, each corresponding to the number of sags recorded at each of the $\mathrm{M}$ monitored sites

\section{B. Physical interpretation of the state variables vector $\mathrm{X}$}

The VSSE method proposed in this paper uses the concept of "fault positions" also applied in stochastic approaches [1][5].

In this approach a number $P$ of fault positions throughout the system will be considered, similarly to the conventional fault positions method. Each fault position will represent a portion of the system. The remaining voltage caused by faults occurring in these portions of the system is approximated to the voltage value caused by a fault occurring exactly at the fault position. This idea is graphically shown in Fig. 1. The graph indicated as "Real $V_{m 1}$ " represents the real remaining voltage, $V_{m 1}$, caused at bus $m_{1}$ of the system when a fault occurs along the considered line. This voltage profile is approximated by the graph shown as "Assumed $V_{m 1}$ " where two fault positions indicated as $p_{1}$ and $p_{2}$ are considered along the line. The voltage threshold $t$ is also represented in Fig. 1.

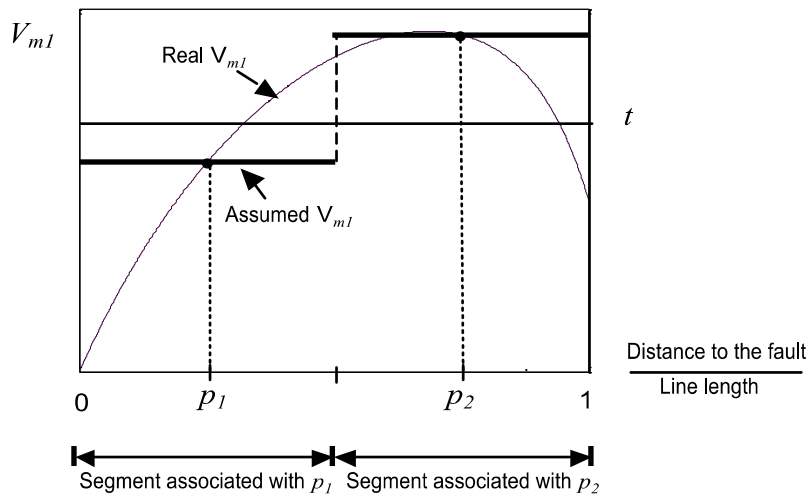

Fig. 1:Real and assumed remaining voltage.

The elements of the state variables vector $\mathbf{X}$ are allocated to each segment of a line represented by a fault position. Therefore, the dimension of $\mathbf{X}$ equals the total number of fault positions $P$. Each element of $\mathrm{X}$, that is each state variable, corresponds to the number of faults occurring in the associated segment.

An interesting characteristic of this method is that state variables correspond to the number of faults, although the aim of the method is calculating the number of sags. Therefore, the number of faults at fault positions is used as an intermediate variable (not even explicitly calculated in the implemented algorithm) from which the number of sags can be derived at a following step. Note that the proposed method is not intended for fault location purposes and that the exact location of faults is not uniquely determined by the formulated system of equations, as it will be further explained in section IV. In this sense, determining exact fault locations is not strictly necessary as far as different 
sets of fault positions can provide very close combinations of expected number of sags.

\section{Construction of Measurement Matrix $\mathbf{M}$}

According to (1), the measurement matrix $\mathbf{M}^{\mathrm{t}}$ (corresponding to a voltage threshold $t$ ) relates the state vector $\mathbf{X}$ to the measurements vector $\mathbf{H}^{\mathrm{t}}$.

Matrix $\mathbf{M}^{\mathrm{t}}$ characterizes the behavior of the entire power system under a faulted scenario. To build this matrix the following steps are followed:

1. Each line of the system is divided into a certain number $p$ of segments. For a network with $l$ lines, the total number of segments in the whole system is $P=l \cdot p$

2. The parameters and topology of the network must be known. By using the modeled network, $P$ shortcircuit analyses are performed assuming a fault at a time in the middle of each one of the $P$ segments.

3. For each of these $P$ assumed faults, the residual voltage at the $M$ monitored buses is calculated.

Next, the residual voltage calculated at the monitored buses is compared with the selected voltage threshold $t$ to form matrix $\mathbf{M}^{\mathbf{t}}$ Therefore, matrix $\mathbf{M}^{\mathrm{t}}$ is a binary matrix of order $(M \times P)$. Each element of $\mathbf{M}^{\mathrm{t}}$ is referred to a monitored bus and to a fault position and takes the value 1 or 0 , according to the following expression:

$$
\mathbf{M}^{\mathrm{t}}=\mathrm{m}^{\mathrm{t}}(m, p)=\left\{\begin{array}{c}
1, \text { if remaining voltage at monitored } \\
\text { bus } m \text { is below } t \text { when faults } \\
\text { occur at segment } p \\
0, \text { if remaining voltage at monitored } \\
\text { bus } m \text { is above } t \text { when faults } \\
\text { occur at segment } p
\end{array}\right.
$$

The formation of $\mathbf{M}^{\mathrm{t}}$ can be easily understood through the example shown in Fig. 1. For the sake of simplicity, in this example only one monitored bus, bus $m_{1}$, is represented. In this example, the elements of matrix $\mathbf{M}^{\mathrm{t}}$ which correspond to the monitored bus $m_{1}$ and to the considered line would result as follows:

$$
\mathbf{M}^{\mathrm{t}}=m_{1}\left[\begin{array}{cccccc}
p_{p_{1}} & p_{2} & & & p_{p} \\
1 & 0 & \cdot & \cdot & \cdot & \cdot \\
\cdot & \cdot & \cdot & \cdot & \cdot & \cdot \\
\cdot & \cdot & \cdot & \cdot & \cdot & \cdot \\
\cdot & \cdot & \cdot & \cdot & \cdot & \cdot \\
\cdot & \cdot & \cdot & \cdot & \cdot & \cdot
\end{array}\right]
$$

Element $\mathrm{m}^{\mathrm{t}}(1,1)$ takes the value 1 , because as observed in Fig. 1, faults within the segment associated with $p_{1}$ produced remaining voltage below the considered threshold, that is, produce voltage sags at monitored bus $m_{1}$. Element $\mathrm{m}^{\mathrm{t}}(1,2)$ is 0 , meaning that faults within the segment associated with fault position $p_{2}$ do not cause sags at bus $m_{1}$.

To consider all the lines of the system, new columns must be added to $\mathbf{M}^{\mathbf{t}}$, each corresponding to a segment of line. It is important to emphasize that matrix $\mathbf{M}^{\mathbf{t}}$ depends only on the characteristics of the considered network. Thus, it is calculated just once for a given network and a given sag threshold.

It is interesting to observe that the selection of the monitoring placement can influence the observability of the network in state estimation. In this work, the monitors placement has been selected by means of the method proposed in [10][18]. This method guarantees that any fault in the system resulting in a sag, triggers at least one monitor. This implies that all the columns of $\mathbf{M}^{\mathrm{t}}$ contain at least one element different from 0 .

\section{Extension to Several Voltage Thresholds}

The terms of (1) have been previously defined for magnitudes calculated for a remaining voltage threshold $t$. This leads to a system of equations as follows:

$$
\mathbf{H}^{\mathrm{t}}=\mathbf{M}^{\mathrm{t}} \mathbf{X} \text {. }
$$

Usually voltage sags monitors can report the number of voltage sags occurring in some discrete bins of remaining voltage. Therefore, the process performed before for a threshold $t$ can be repeated in an analogous way for another voltage threshold. Systems of equations similar to (3) can be obtained by constructing the measurements vector and the measurements matrix for a number $T$ of different voltage thresholds. This leads to a system given by

$$
\left(\begin{array}{c}
\mathbf{H}^{1} \\
\mathbf{H}^{2} \\
\cdot \\
\cdot \\
\mathbf{H}^{\mathrm{t}} \\
\cdot \\
\cdot \\
\mathbf{H}^{\mathrm{T}}
\end{array}\right)=\left(\begin{array}{c}
\mathbf{M}^{1} \\
\mathbf{M}^{2} \\
\cdot \\
\cdot \\
\mathbf{M}^{\mathrm{t}} \\
\cdot \\
\mathbf{M}^{\mathrm{T}}
\end{array}\right) \mathbf{X}
$$

where

$\mathbf{H}^{1}, \mathbf{H}^{2}, \ldots, \mathbf{H}^{\mathrm{t}}, \ldots, \mathbf{H}^{\mathrm{T}}$ are the measurement vectors formed by the number of sags recorded at monitored buses, for a threshold $t=1,2, \ldots, \mathrm{t}, \ldots T$.

$\mathbf{M}^{1}, \mathbf{M}^{2}, \ldots, \mathbf{M}^{\mathrm{t}}, \ldots, \mathbf{M}^{\mathrm{T}}$ are the binary measurement matrices corresponding to thresholds $t=1,2, \ldots, \mathrm{t}, \ldots T$.

$\mathbf{X}$ is the state variables vector.

$$
\text { Equation (4) can be expressed in a compact form as }
$$$$
\mathbf{H}=\mathbf{M} \mathbf{X} \text {. }
$$

\section{SOLUTION OF THE SYSTEM EQUATIONS}

The system of equations (5) is constituted by $P$ unknowns and $M \cdot T$ equations. Often, in a real power system, using a partial, or even a complete, monitoring program this system leads to an underdetermined VSSE problem. That implies that multiple solutions verify the system of equations (5). For such problems, the SVD technique can provide a particular solution of quadratic minimum norm. This methodology has previously been proposed for the estimation of other power quality disturbances [13]-[16].

Next, a short explanation of this mathematical tool is included.

\section{A. SVD Method}

The SVD is a widely used technique to decompose a matrix into several component matrices, exposing many useful and interesting properties. Therefore, the SVD approach permits representing rectangular matrix $\mathbf{M}$ as the product of three matrices:

$$
\mathbf{M}=\mathbf{U S V}^{\prime}
$$

where 
$\mathbf{U}$ is a orthogonal $(M \cdot T) \times(M \cdot T)$ matrix,

$\mathbf{V}$ is a orthogonal $P \times P$ matrix and $\mathbf{V}^{\prime}$ is the transpose of V,

$\mathrm{S}$ is a diagonal matrix of dimension $(M \cdot T) \times P$ with positive or zero elements, which are the singular values.

This decomposition can always be performed, no matter the dimension or how singular the original matrix is.

Before operating with matrices $\mathbf{U}, \mathbf{V}$ and $\mathbf{S}$, they must be modified according to the rank. If the rank of the system is $r$, the essential information is contained in $r$ linearly independent equations: that is, in the $r$ non-zero singular values of $\mathbf{S}$ and the $r$ non-singular vectors of $\mathbf{U}$ and $\mathbf{V}$. Therefore, matrices of (6) must be transformed into the reduced size matrices by $\mathbf{U}_{\mathbf{r}}, \mathbf{S}_{\mathbf{r}}$ and $\mathbf{V}_{\mathbf{r}}$. These reduced size matrices $\mathbf{U}_{\mathbf{r}}$ and $\mathbf{V}_{\mathbf{r}}$ are obtained from the original by keeping the first $r$ columns of $\mathbf{U}$ and the first $r$ rows of $\mathbf{V}$. Matrix $\mathbf{S}$ is modified to take only the $r$ non-zero singular values to became a $r \times r$ matrix.

Considering (6) and the aforementioned size reduction, the solution of (5) can be obtained as

$$
X=\mathbf{V}_{\mathbf{r}} \mathbf{S}_{\mathbf{r}}^{-1} \mathbf{U}_{\mathbf{r}}^{\prime} \mathbf{H}_{\mathbf{r}}
$$

\section{B. Solution Analysis: Estimation of the Number of Voltage Sags}

The previous procedure permits the estimation of the state variables vector $\mathbf{X}$.

The last step of the VSSE is to calculate the expected number of voltage sags at the buses of interest from the estimated vector $\mathbf{X}$. To do this, a binary matrix, $\mathbf{M}_{\mathbf{n m}}$, is built; matrix $\mathbf{M}_{\mathbf{n m}}$ is then formed exactly as matrix $\mathbf{M}$ but, in this case, applied to the non-monitored buses instead to the monitored buses. That is, matrix $\mathbf{M}_{\mathbf{n m}}$ would be calculated similarly to the example matrix shown in (2), but rows would be referred to as the unmetered buses. Therefore, the elements of $\mathbf{M}_{\mathbf{n m}}$ are formed as follows:

$$
\mathbf{M}_{\mathrm{nm}}^{\mathrm{t}}=\mathrm{m}_{\mathrm{nm}}^{\mathrm{t}}(m, p)=\left\{\begin{array}{c}
1, \text { if remaining voltage at non-monitored } \\
\text { bus mis below } t \text { when faults occur } \\
\quad \text { at segment } p \\
0, \text { if remaining voltage at non-monitored } \\
\text { bus } m \text { is above } t \text { when faults occur } \\
\text { at segment } p
\end{array}\right.
$$

If this matrix $\mathbf{M}_{\mathbf{n m}}^{\mathrm{t}}$ is multiplied by the state variables vector determined in (7), the number of sags $\mathbf{H}_{\mathbf{n m}}^{\mathrm{t}}$ is calculated as

$$
\mathbf{H}_{\mathrm{nm}}^{\mathrm{t}}=\mathbf{M}_{\mathrm{nm}}^{\mathrm{t}} \mathbf{X}
$$

where $\mathbf{H}_{\mathbf{n m}}^{\mathrm{t}}$ is a vector whose elements indicate the estimated number of sags at non-monitored buses for threshold $t$.

Equation (8) is solved by means of (7) as

$$
\mathbf{H}_{n m}^{\mathrm{t}}=\mathbf{M}_{\mathbf{n m}}^{\mathrm{t}} \mathbf{V}_{\mathbf{r}} \mathbf{S}_{\mathbf{r}}^{-1} \mathbf{U}_{\mathbf{r}}^{\prime} \mathbf{H}_{\mathbf{r}} \text {. }
$$

This process can be applied at any bus of interest and for any voltage threshold.

\section{Considerations in the Presented Work}

The method presented in this paper has performed well in the simulated cases. Some additional considerations regarding the presented work are explained next.

\section{- $\quad$ About measurement errors}

The influence of measurement errors in the state estimation has not been analyzed, and further work should consider this aspect. However, a significantly advantageous characteristic of the proposed formulation is that it only requires a classification of the number of measured sags in discrete bins. That is, the exact voltage magnitude of the sag is not considered. This fact contributes to a great extent in limiting the influence of measuring errors.

\section{- $\quad$ About the number of fault positions considered}

As a consequence of the discrepancies between the real voltage profile and the approximation made by the fault positions assumption (see Fig. 1), the calculated measurements matrix $\mathbf{M}$ has implicit errors. This can be easily understood by means of Fig. 1 where only two fault positions are assumed along the line. Since a fault at $p_{1}$ causes a sag, all the faults occurring along the first segment of the line are considered as causing a sag and, therefore, are represented by a value 1 in the corresponding element of matrix M. However, if faults occur at the end of this segment, the real voltage profile is over the threshold, as seen in Fig. 1, and, consequently, these faults do not cause a sag.

Therefore, some of the equations contained in systems (5) and (9) can be inexact. This problem can be readily minimized by considering a larger number of fault positions along the line. However, increasing the number of fault positions implies increasing the number of state variables and, therefore, the system of equations becomes more underdetermined. A compromise should be therefore found in the number of selected fault positions in the lines. This aspect will be further analyzed from a practical point of view in the presented case studies.

- $\quad$ About different types of fault.

In the theoretical part of this work, the mathematical expressions have been developed for a single type of fault. A more realistic approach should consider the simultaneous occurrence of different types of faults. This problem could be solved by applying an appropriate method for faults identification at the metered buses. The VSSE could then be applied to each type of fault.

One of the case studies presented in the next section examines this methodology.

\section{STUDIES IN THE IEEE 118 TEST SYSTEM}

The IEEE 118 test system consists of 36 generating stations, 118 buses interconnected by 177 lines and nine transformers. The data system is provided in [19].

The validation of the proposed approach is checked by means of the following procedure:

1) For each line of the system, a random number and location of faults is generated.

2) By means of classical short circuit calculations, the number of sags that would be caused by the fault scenario assumed in 1) is calculated for any bus $j$. This constitutes $\mathrm{NS}_{\text {realj}}$.

3) The monitored buses are selected. The measurement vector $\mathbf{H}$ is formed with the number of sags 
calculated in 2) for the monitored buses. Therefore, these values are considered "pseudo-measurements" that would be registered by hypothetical monitors installed at those buses when submitted to the fault scenario of step 1).

4) By considering the pseudo-measurements vector $\mathbf{H}$, the proposed VSSE method is applied. The number of sags at any bus $j$ is estimated by means of the VSSE method, and this constitutes $\mathrm{NS}_{\text {est }}$.

5) The value obtained in 4), $\mathrm{NS}_{\text {estj, }}$, is compared with the number of sags calculated in step 2), $\mathrm{NS}_{\text {realj. This }}$ comparison permits the analysis of the accuracy of the estimation method.

\section{A. Base Case Study}

In this case study, a random number of faults with average 3 and typical deviation 1 has been generated as previously described in step 1). The position of occurrence of each fault along the line has been obtained randomly assuming uniform faults probability along the length of the line. The faults rate at the buses has been assumed negligible [20], and all the faults in the lines are assumed single-phase-to-ground faults.

The number and location of monitors have been calculated by applying the methodology proposed in [18].

The application of this method leads to placing 20 monitors at buses 15, 22, 24, 42, 43, 47, 49, 58, 62, 69, 70, 78, 86, 97, 98, 99, 102, 109, 115 and 117. In this case study, VSSE has been applied considering 10 fault positions in each line. That means that 10 state variables per line are used, which leads to 1770 unknowns.

Fig. 2, Fig. 3 and Fig. 4 show the real and the estimated number of voltage sags at all the buses of the system for voltage thresholds of 0,9 p.u., 0,8 p.u. and 0,7 p.u., respectively. The number of sags estimated by the proposed algorithm at non-monitors sites shows a good agreement with real values, as seen in the figures.

The relative error at a generic bus $j\left(\mathrm{RE}_{j}\right)$ between the estimated number of sags and the real number of sags can be calculated for each bus with the following expression

$$
\mathrm{RE}_{j}(\%)=\left|\frac{\mathrm{NS}_{\text {est } j}-\mathrm{NS}_{\text {real } j}}{\mathrm{NS}_{\text {real } j}}\right| \times 100 \text {. }
$$

The absolute value of (10) has been considered in order not to compensate the positive and negative errors.

Table I shows the average $\mathrm{RE}_{j}$ error calculated by means of (10). Note that the best results of the method are provided for estimating the number of sags with voltage below 0.9 p.u. The average error increases as the remaining voltage threshold considered for the estimation decreases. This is a logical trend, since deeper sags occur closer to the fault location and, therefore, a lower number of monitors can record them, which makes the estimation less precise. Table I also shows the average and maximum absolute error of the estimation.

Not only site indices, but also system indices can be calculated with the proposed approach. Fig. 5 and Fig. 6 show the performance of the system for voltage sags below 0.9 p.u. and 0.7 p.u., respectively. These figures, similarly to the measurements provided in [21], provide the real and estimated percentage of sites that experience a certain amount of voltage sags. For instance, around $17 \%$ of sites have between 120 and 130 voltage sags with voltage below 0.9 p.u. For the remaining voltage below 0.7 p.u., approximately $35 \%$ of the sites experience between 30 and 40 voltage sags. Clearly, by this method, a good characterization of the whole system in terms of sags can be obtained although only a partial monitoring program is applied (only 20 of the 118 buses are monitored buses).

Table II compares the real average number of sags in the system with the estimated average. The estimated value is very close to the actual value.

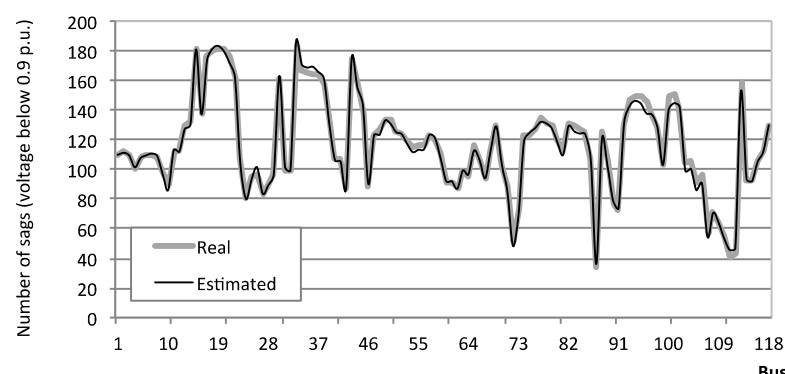

Fig. 2: Actual and estimated number of voltage sags with residual voltage below 0.9 p.u. at the IEEE 118 test system buses.

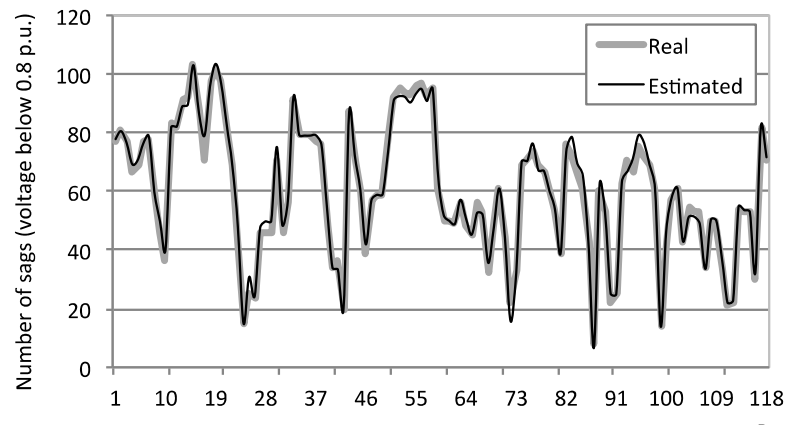

Bus

Fig. 3: Actual and estimated number of voltage sags with residual voltage below 0.8 p.u.at the IEEE 118 test system buses.

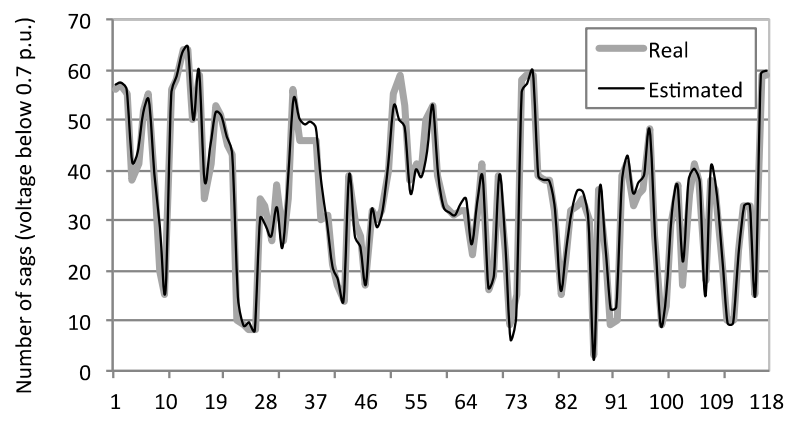

Fig. 4: Actual and estimated number of voltage sags with residual voltage below 0.7 p.u.at the IEEE 118 test system buses.

TABLE I:

ERROR APPLYING VSSE AT THE 118 BUS SYSTEM

\begin{tabular}{|c|c|c|c|}
\hline \multirow{2}{*}{} & \multicolumn{3}{|c|}{$\begin{array}{c}\text { VSSE of sags with remaining } \\
\text { voltage below: }\end{array}$} \\
\cline { 2 - 4 } & 0.9 p.u. & 0.8 p.u. & 0.7 p.u. \\
\hline Average $\mathrm{RE}_{\mathrm{j}}$ & $1.9 \%$ & $3.43 \%$ & $6.67 \%$ \\
\hline Average absolute error & 2.1 & 1.7 & 1.7 \\
\hline Maximum absolute error & 9.8 & 8.0 & 9.0 \\
\hline
\end{tabular}




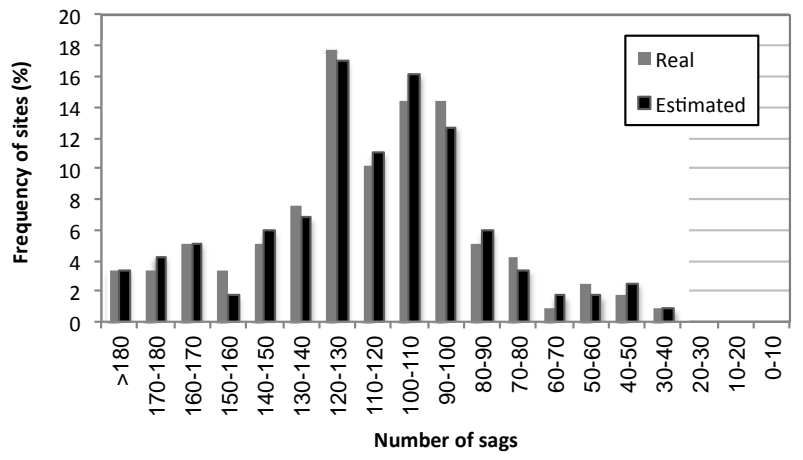

Fig. 5: Frequency of sites having a certain number of sags with remaining voltage below 0.9 p.u.

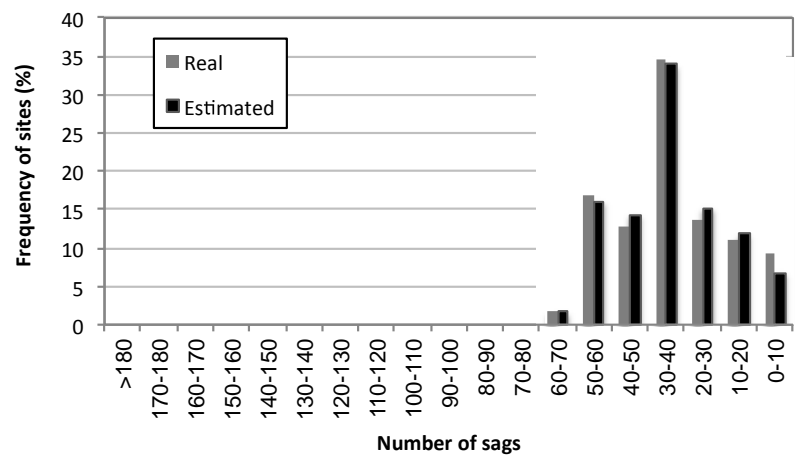

Fig. 6: Frequency of sites having a certain number of sags with remaining voltage below 0.7 p.u.

TABLE II:

AVERAGE NUMBER OF VOLTAGE SAGS IN THE WHOLE SYSTEM

\begin{tabular}{|c|c|c|c|}
\hline \multirow{2}{*}{$\begin{array}{c}\text { Threshold } \\
\text { setting }\end{array}$} & \multicolumn{2}{|c|}{$\begin{array}{c}\text { Average number of } \\
\text { sags in the system }\end{array}$} & \multirow{2}{*}{ Error \% } \\
\cline { 2 - 3 } & Real & VSSE & \\
\hline 0.9 & 117.23 & 116.36 & 0.74 \\
\hline 0.8 & 60.47 & 61.03 & -0.94 \\
\hline 0.7 & 34.54 & 34.91 & -1.06 \\
\hline
\end{tabular}

\section{B. Influence of the Number of Fault Positions}

In the preceding section, the proposed VSSE method has been applied by considering 10 fault positions along each line. As previously discussed in Section VI, increasing the considered number of fault positions has a double effect:

- On one hand, this also implies increasing the number of unknowns of the system of equations.

- On the other hand, increasing the number of faults positions permits a better determination of the voltage profile caused by the faults along the line and, consequently, a more exact determination of the measurement matrix $\mathbf{M}$.

This section investigates the influence of the number of fault positions considered in the results obtained by the proposed VSSE method. Table III shows the average of the estimation $\mathrm{RE}_{j}$ obtained at each bus of the system considering 3,10 or 15 fault positions. In general, as revealed in the Fig. 7, the higher the considered number of fault positions, the lower the obtained error.

TABLE III:

AVERAGE ERROR APPLYING VSSE WITH DIFFERENT NUMBER OF FAULT POSITIONS

\begin{tabular}{|c|c|c|c|}
\hline \multirow{3}{*}{$\begin{array}{l}\text { Remaining } \\
\text { voltage } \\
\text { (p.u.) }\end{array}$} & \multirow{2}{*}{\multicolumn{3}{|c|}{$\begin{array}{c}\text { Average } \mathrm{RE}_{\mathrm{j}}(\%) \\
\begin{array}{c}\text { Number of fault positions } \\
\text { along lines }\end{array}\end{array}$}} \\
\hline & & & \\
\hline & 3 & 10 & 15 \\
\hline 0.9 & 1.72 & 1.84 & 1.84 \\
\hline 0.8 & 4.98 & 3.29 & 3.41 \\
\hline 0.7 & 13.32 & 5.99 & 5.83 \\
\hline
\end{tabular}

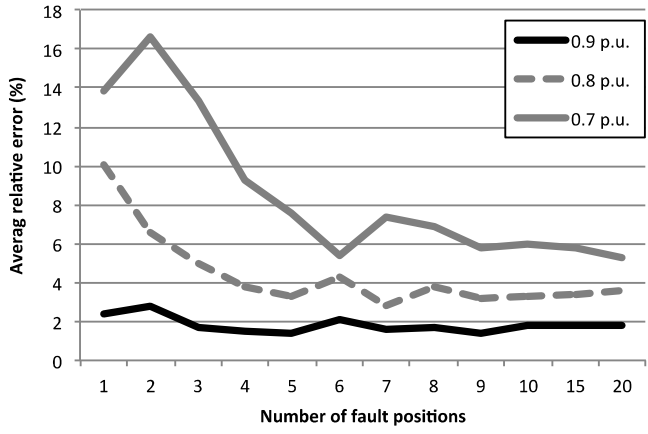

Fig. 7: Average $\mathrm{RE}_{\mathrm{j}}(\%)$ in the estimation of the number of sags by considering different numbers of fault positions.

\section{Influence of the Number of Monitors}

The number of monitors installed in the system is a factor that can clearly influence the results of the estimation. The lower the number of monitors the more incertitude in the estimation and, conversely, an increase in the number of installed monitors allows more accurate estimation results.

This fact is confirmed by the case study presented in this section. The estimation provided by the previously analyzed case where 20 monitors were considered is compared with two different cases with eight and 45 monitors. In both cases, the monitor location has been selected again by means of the method [18] by selecting different thresholds for triggering at least one monitor. In the case of 8 monitors, these are located at buses $16,22,43,50,75,88,101$ and 103. The location, in the case of 45 monitors, is at buses 3 , $10,13,14,16,20,24,25,31,33,37,41,42,44,46,47,48$, $49,50,51,52,54,55,60,61,66,67,69,70,72,76,80,86$, 89, 93, 97, 98, 99, 102, 105, 106, 110, 113, 114 and 117.

Fig. 8 shows the $\mathrm{RE}_{j}$ obtained by (10) for the estimated number of sags with remaining voltage below 0.9 p.u. Note that the error reaches larger values when only 8 buses are monitored among the 118 buses of the system. Table IV provides the average of $\mathrm{RE}_{j}$ and the 90th percentile of the error when a different number of monitors are involved. Ninety percent of the buses have an estimation error lower than $7.83 \%$ when only 8 monitors are installed. In the case where 20 monitors are installed, then the number of sags estimated in $90 \%$ of the buses has an error lower than 4.84 . For 45 monitors, $90 \%$ of the buses have $\mathrm{RE}_{j}$ lower than $3.12 \%$.

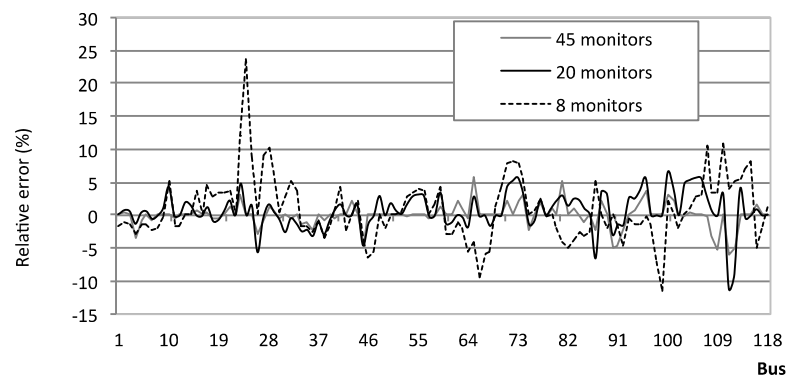

Fig. 8: Relative error in the estimation of the number of sags with remaining voltage below 0.9 p.u.

TABLE IV:

VSSE PERFORMANCE WITH DIFFERENT NUMBER OF MONITORS. SAGS WITH REMAINING VOLTAGE BELOW 0.9 P.U.

\begin{tabular}{|c|c|c|c|}
\hline & \multicolumn{3}{|c|}{ Number of monitors } \\
\hline & 8 & 20 & 45 \\
\hline Average $\mathrm{RE}_{\mathrm{j}}(\%)$ & 3.40 & 1.90 & 0.96 \\
\hline 90th Percentile $\mathrm{RE}_{\mathrm{j}}(\%)$ & 7.83 & 4.84 & 3.12 \\
\hline
\end{tabular}




\section{Different Fault Scenarios and Different Periods of Measurement}

In this section the performance of the proposed method is tested for different fault scenarios. Twelve cases are displayed which have been obtained for different numbers and locations of faults, both randomly selected. In cases 1 to 4, (shown in Table V) the average number of faults per line is 0.5 with a typical deviation of $40 \%$ (for cases 1 and 2) and $80 \%$ (for cases 3 and 4). Table VI, shows cases 5 to 8 . These cases have been generated for different fault scenarios where the number of faults per line is a random number with average 3 and a typical deviation of $40 \%$ and $80 \%$. Finally, Table VII includes cases 9 to 12 which are obtained by considering an average of 5 faults per line and the same typical deviation as in previous cases. The location of faults has been randomly selected in all the cases assuming uniform fault probability along the whole length of the lines.

The cases generated by considering lower number of faults can be representative of measurements performed during short periods of measurement. Obviously, the shorter the monitoring period, the lower the number of recorded events. On the contrary, larger numbers of faults occurrences can appear if longer monitoring periods are considered. The number of voltage sags estimated by the VSSE method is referred to the same monitoring period as the measurements used for the estimation. For instance, if the number of sags is measured at the monitored sites during one year, the number of sags estimated at the nonmonitored sites also corresponds to the sags which occurred during the year.

As revealed in Table V, Table VI and Table VII, the proposed VSSE method obtains satisfactory results in all the cases. The average $\mathrm{RE}_{j}$ is similar in all the scenarios performed with similar number of faults. However, relative error tends to increase in the scenarios with lower number of faults; that is, those with a lower number of voltage sags. This is a sound result taking into account that relative error rises drastically when determined for very low real values. In the limit situation, for a real value of zero sags, even small absolute errors would cause infinite relative error. $\mathrm{RE}_{j}$ decreases when longer periods of measurement (with larger numbers of recorded events) are considered.

The average and maximum absolute errors are also displayed in Table V, Table VI and Table VII. From these tables one can deduce that the method is reliable and that provides reasonable results independently of the considered scenario.

\section{E. Different Types of Fault}

In previous sections, a single type of fault has been assumed in the analyzed situations. In this case study, the performance of the presented formulation is checked when different types of faults are considered as occurring simultaneously. Under these circumstances, an appropriate method (like those proposed in [22][23][24]), should be employed at the metered buses for faults identification. With this, different types of faults can be classified, VSSE can be applied independently to each type and, next, the results can be aggregated. This problem does not complicate the VSSE method, although it implies solving more equations.

A case study has been simulated where different types of faults are considered. Seventy percent of them have been assumed to be phase-to-ground faults, $15 \%$ are phase-tophase shortcircuits, $10 \%$ are phase-to-phase-to-ground faults and 5\% are three-phase faults. The real and estimated numbers of sags caused by each type of fault are shown in Fig. 9. Table VIII reports the average error obtained for the number of sags originated by each type of fault and the error in the total number of sags (caused simultaneously by all the faults of different types).

TABLE V:

VSSE PERFORMANCE FOR DIFFERENT FAULT SCENARIOS.

\begin{tabular}{|c|c|c|c|c|}
\multicolumn{2}{|c|}{} & \multicolumn{4}{|c|}{ Scenario number } \\
\cline { 2 - 5 } & Case 1 & Case 2 & Case 3 & Case 4 \\
\hline $\begin{array}{c}\text { Average number } \\
\text { of faults per line }\end{array}$ & \multicolumn{4}{|c|}{0.5} \\
\hline $\begin{array}{c}\text { Standard deviation (number } \\
\text { of faults/line) }\end{array}$ & \multicolumn{2}{|c|}{0.2} & \multicolumn{2}{|c|}{0.4} \\
\hline $\begin{array}{c}\text { Total number of faults } \\
\text { generated in the system }\end{array}$ & 84 & 85 & 87 & 103 \\
\hline $\begin{array}{c}\text { Average RE } \text { (\%) } \\
\text { Average absolute error }\end{array}$ & 3.93 & 3.59 & 3.39 & 2.91 \\
\hline \begin{tabular}{c} 
Maximum absolute error \\
\hline $\begin{array}{c}\text { Real average number of } \\
\text { sags in the system } \\
\text { (threshold 0.9 p.u.) }\end{array}$
\end{tabular} & 2.80 & 2.81 & 3.62 & 2.86 \\
\hline $\begin{array}{c}\text { Estimated average number } \\
\text { of sags in the system } \\
\text { (threshold 0.9 p.u.) }\end{array}$ & 16.98 & 20.57 & 20.40 & 22.63 \\
\hline
\end{tabular}

VSSE PERFORMANCE FOR DIFFERENT FAULT SCENARIOS. CASES 5 TO 8

\begin{tabular}{|c|c|c|c|c|}
\hline & \multicolumn{4}{|c|}{ Scenario number } \\
\hline & Case 5 & Case 6 & Case 7 & Case 8 \\
\hline $\begin{array}{l}\text { Average number } \\
\text { of faults per line }\end{array}$ & \multicolumn{4}{|c|}{3} \\
\hline $\begin{array}{c}\text { Standard deviation (number } \\
\text { of faults/line) }\end{array}$ & \multicolumn{2}{|c|}{1.2} & \multicolumn{2}{|c|}{2.4} \\
\hline $\begin{array}{l}\text { Total number of faults } \\
\text { generated in the system }\end{array}$ & 523 & 526 & 542 & 529 \\
\hline Average $\mathrm{RE}_{j}(\%)$ & 1.64 & 1.92 & 2.09 & 1.38 \\
\hline Average absolute error & 1.73 & 2.22 & 2.23 & 1.61 \\
\hline Maximum absolute error & 6.32 & 13.71 & 11.82 & 7.42 \\
\hline $\begin{array}{l}\text { Real average number of } \\
\text { sags in the system } \\
\text { (threshold } 0.9 \text { p.u.) }\end{array}$ & 115.84 & 117.24 & 116.97 & 119.18 \\
\hline $\begin{array}{l}\text { Estimated average number } \\
\text { of sags in the system } \\
\text { (threshold } 0.9 \text { p.u.) }\end{array}$ & 115.15 & 116.41 & 117.20 & 118.61 \\
\hline
\end{tabular}

VSSE PERFORMANCE FOR DIFFERENT FAULT SCENARIOS. CASES 9 TO 12

\begin{tabular}{|c|c|c|c|c|}
\hline & \multicolumn{4}{|c|}{ Scenario number } \\
\cline { 2 - 5 } & Case 9 & Case 10 & Case 11 & Case 12 \\
\hline $\begin{array}{c}\text { Average number } \\
\text { of faults per line }\end{array}$ & \multicolumn{4}{|c|}{5} \\
\hline $\begin{array}{c}\text { Standard deviation } \\
\text { (number of faults/line) }\end{array}$ & \multicolumn{2}{|c|}{2} & \multicolumn{2}{|c|}{4} \\
\hline $\begin{array}{c}\text { Total number of faults } \\
\text { generated in the system }\end{array}$ & 894 & 865 & 880 & 990 \\
\hline Average RE $E_{\text { }} \%$ ) & 1.57 & 1.25 & 1.89 & 1.46 \\
\hline $\begin{array}{c}\text { Average absolute error } \\
\text { Maximum absolute error }\end{array}$ & 14.55 & 8.5 & 16.05 & 18.13 \\
\hline $\begin{array}{c}\text { Real average number of } \\
\text { sags in the system } \\
\text { (threshold 0.9 p.u.) }\end{array}$ & 199.64 & 187.57 & 193.95 & 216.96 \\
\hline $\begin{array}{c}\text { Estimated average number } \\
\text { of sags in the system } \\
\text { (threshold 0.9 p.u.) }\end{array}$ & 200.07 & 187.18 & 192.16 & 216.27 \\
\hline
\end{tabular}




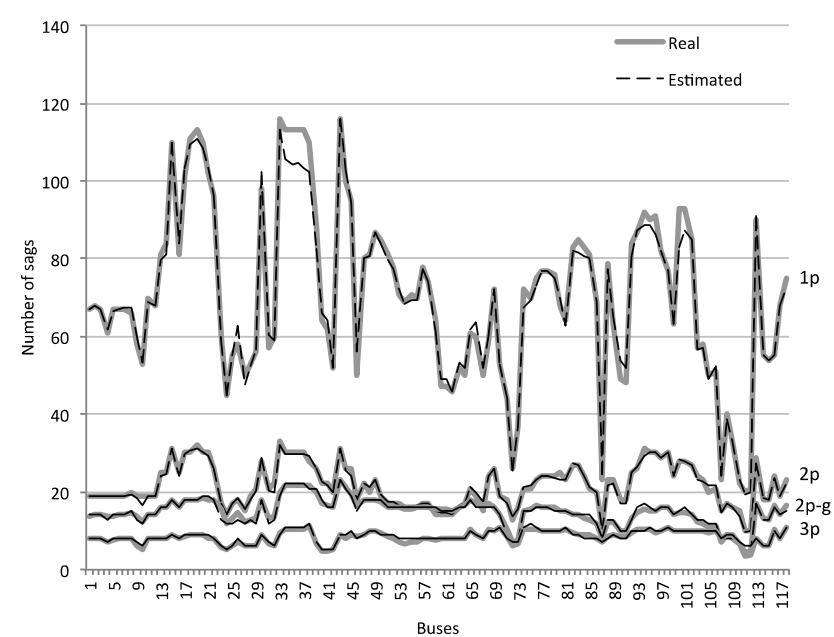

Fig. 9: Actual and estimated number of voltage sags with residual voltage below 0.9 p.u. for different types of fault. TABLE VIII:

VSSE PERFORMANCE FOR DIFFERENT TYPES OF FAULT. SAGS WITH REMAINING VOLTAGE BELOW 0.9 P.U.

\begin{tabular}{|c|c|c|c|c|c|}
\hline & \multicolumn{4}{|c|}{ Type of fault } & \multirow{2}{*}{$\begin{array}{c}\text { Total } \\
\text { No sags }\end{array}$} \\
\hline & $1 \mathrm{p}$ & $2 \mathrm{p}$ & $2 \mathrm{p}-\mathrm{g}$ & $3 \mathrm{p}$ & Nonnnnn \\
\hline Average $\mathrm{RE}_{j}(\%)$ & 2.47 & 2.33 & 3.33 & 4.14 & 1.72 \\
\hline 90th Percentile $\mathrm{RE}_{j}(\%)$ & 5.94 & 5.57 & 9.20 & 9.09 & 4.71 \\
\hline
\end{tabular}

\section{CONCLUSION}

This paper has proposed a method for estimating the voltage sags performance at non-monitored buses using the data recorded at the monitored sites. The formulation applied is based on the concept of fault positions to approximate the residual voltage caused by faults occurring along lines. This approach leads to a much simpler mathematical formulation than previous approaches. The solution of the problem is obtained by means of SVD.

The presented VSSE method has been implemented and applied to the IEEE 118 bus test system. By the presented case studies, the influence of different parameters on the proposed methodology has been analyzed. In general, this method provides very satisfactory results estimating the voltage sag performance of particular non-monitored sites, as well as the performance of the electric system as a whole.

\section{REFERENCES}

[1] M. H. J. Bollen, "Understanding power quality problems. Voltage sags and interruptions,” IEEE PRESS Series on Power Engineering, 2000.

[2] D. L. Brooks, R. C. Dugan, M. Waclawiak, A. Sundaram, "Indices for assessing utility distribution system RMS variation performance," IEEE Trans. on Power Delivery, vol. 13, no. 1, pp. 254-259, Jan 1998.

[3] G. Beaulieu, M. H. J. Bolen, S. Malgarotti, R. Ball and other CIGRE Working group 36-07 members, "Power quality indices and objectives ongoing activities in CIGRE WG 36-07,” IEEE Power Engineering Society Summer Meeting 2002, vol. 2, pp.789 - 794, July 2002.

[4] IEEE Voltage Sags Indices, Draft 4, working document for IEEE 1564 Sep. 2003.

[5] M. R. Qader, M. H. J. Bollen, "Stochastic prediction of voltage sags in a large transmission system,” IEEE Trans. Industry Application, vol. 35, no. 1, pp. 152-162, Jan. 1999.

[6] J. V. Milanovic, M. T. Aung, C. P. Gupta, "The influence of fault distribution on stochastic prediction of voltage sags," IEEE Trans. Power Delivery, vol. 20, no. 1, pp. 278-285, Jan. 2005.

[7] E. Espinosa, A. Hernández, "An analytical approach for stochastic assessment of balanced and unbalanced voltage sags in large systems,” IEEE Trans. on Power Delivery, vol. 21, no. 3, pp. 1493-1500, Jul. 2006.

[8] B. Wang, W. Xu, Z. Pan, "Voltage sag state estimation for power distribution systems," IEEE Trans. on Power Systems, vol. 20, no. 2, pp. 806-812, May. 2005.
[9] E. Espinosa Juárez, A. Hernández, “A method for voltage sag state estimation in power systems," IEEE Trans. on Power Delivery, vol. 22, no. 4, pp. 2517-2526, Oct. 2007.

[10] G. Olguin, F.Vuinovich, M. H. J. Bollen, "An optimal monitoring program for obtaining voltage sag system indexes," IEEE Transaction on Power Systems, vol. 21, no. 1, pp. 378-384, Feb. 2006.

[11] J. Lucio, E. Espinosa-Juárez, A. Hernández, "Voltage sag state estimation in power systems by applying genetic algorithms,” IET Generation, Transmission \& Distribution, 2011, vol. 2, pp. 223-230.

[12] E. EspinosaJuárez, A. Hernández, "Voltage sag state estimation: An approach based on the concept of fault positions", in Proc. International Conference on Harmonics and Quality of Power (ICHQP), Cascais, Portugal, Oct.2006.

[13] S. S. Matair, N. R. Watson, K. P. Wong, V. L. Pham, J. Arrillaga, "Harmonic state estimation: A method for remote harmonic assessment in a deregulated utility network,” in Proc. IEEE Int. Conf. Electric Utility Deregulation and Restructuring and Power Technologies 2000, London, U.K., Apr. 4-7, 2000, pp. 41-46.

[14] T. Lobos, T. Kozina, H. J. Koglin, "Power system harmonics estimation using linear least squares method and SVD,” IEE Proc.Gener. Transm. Distrib., vol. 148, no. 6, Nov. 2001.

[15] K. K. C. Yu, N. R. Watson, "Three-phase harmonic state estimation using SVD for partially observable systems,” International Conference on Power System Technology, POWERCON 2004, vol. 1, pp. 29-34 Nov. 2004.

[16] N. R. Watson, "Power quality state estimation," European Transactions on Electrical Power, vol. 20, no. 1, pp. 19-33, Jan. 2010.

[17] J. J. Grainger, W. D. Stevenson. "Power System Analysis," Ed. McGraw-Hill, Inc., U.S.A., 1994.

[18] E. Espinosa-Juarez, A. Hernández, G. Olguin, "An approach based on analytical expressions for optimal location of voltage sag monitors," IEEE Trans. on Power Delivery, 2009, vol. 24, no. 4, pp. 2034-2042.

[19] R. Christie, "Power flow test cases, 118 bus power flow test case," University of Washington, College of Engineering, Electrical Engineering, May 1993. [Online] Available: http: //www.ee. washington.edu/research/pstca/.

[20] IEEE Recommended practice for monitoring electric power quality, IEEE Std 1159-1995, Nov. 1995.

[21] IEC 61000-2-8 Ed.1 Environment-Voltage dips and short interruptions on public electric power supply systems with statistical measurement results, Feb. 2002

[22] M. H. J. Bollen, "Algorithms for characterizing measured three-phase unbalanced voltage dips,” IEEE Trans. Power Delivery, vol. 18, no. 3, pp. 937-944, Jul. 2003.

[23] R. C. Leborgne, D. Karlsson, "Phasor based voltage sag monitoring and characterization,” 18th International Conference and Exhibition on Electricity Distribution, 2005 (CIRED 2005), Turin, Italy, Jun. 2005.

[24] M. B. I. Reaz, MF. Choong, M. S. Sulaiman, F. Mohd-Yasin, M Kamada, "Expert system for power quality disturbance classifier," IEEE Trans. Power Delivery, vol. 22, no. 3, pp. 1979-1988, Jul. 2007.

\section{BIOGRAPHIES}

Araceli Hernández (M’2006) graduated in Electrical Engineering from the Universidad Politécnica de Madrid (UPM), Spain, in 1996. In 2000 she received her Ph.D. degree and joined the Department of Electrical Engineering in the UPM where she works presently as an associate professor.

Elisa Espinosa Juárez (M’2007) graduated in Electrical Engineering from the Universidad Michoacana de San Nicolás de Hidalgo (UMSNH), México, in 1986, received the M.Sc. degree from the Instituto Politécnico Nacional, México D.F., México, in 2001, and the Ph.D. degree from the UPM in 2006. Currently, she is a professor with the UMSNH, Morelia, México. Her research interests include power quality and, especially, voltage sags.

Rosa María de Castro graduated in Electrical Engineering from the Universidad Politécnica de Madrid (UPM), Spain, in 1996. In 2001, she joined the Department of Electrical Engineering in the UPM, where she works currently as an assistant professor. Her research interests include power system analysis and voltage stability.

Mohamed Izzeddine graduated in Electrical Engineering from Universidad Politécnica de Madrid (UPM), Madrid, Spain, in 1989. In 1986, he joined the Department of Electrical Engineering at UPM, where he is currently as an associate professor. His research interests include all areas concerning power quality. 